\title{
Priorities of Ophthalmic Research
}

\author{
George L. Spaeth \\ Glaucoma Service Foundation to Prevent Blindness, Wills Eye Institute, Philadelphia, Pa., USA
}

\author{
Key Words \\ Priorities $\cdot$ Validity $\cdot$ Relevance $\cdot$ New ideas $\cdot$ Statistical \\ significance $\cdot$ Funding $\cdot$ Research purpose $\cdot$ Social \\ responsibility
}

\begin{abstract}
The purpose of research is to uncover truths, that is to describe reality validly. But all truths are not equally generalizable, and all research is not equally justifiable. For example, the value of a study that requires an $\mathrm{N}$ of 100,000 to reach statistical significance (a presumed truth) is likely to be far less than that of a study requiring only an $\mathrm{N}$ of 10 . Furthermore, the value of research is related to the relevance of the finding to the 'great issues'. In the field of health, the two great issues are function and feeling - the capacity to act and the quality of life. Investigators, universities, mentors, and funding sources need to consider truthfully whether a proposed research project is directed towards uncovering a relevant truth, one that has a reasonable chance of improving function and/or feeling, or leading to findings that will improve function or feeling. The development of a useless or harmful product, the publication of an irrelevant paper, the support of a 'brilliant investigator', and the development of a prestigious department are not adequate justifications for performing research. The consequences of the present system - driven by financial gain, power, and prestige - are exemplified in the comparison of the large amount of funds being expended to improve cataract surgery (which is al-
\end{abstract}

ready an incredibly successful procedure), yet at the same time almost no funds are being spent to study how to detect people with glaucoma who will go blind, fully $1 \%$ of the world's population.

Copyright $\odot 2012$ S. Karger AG, Basel

The prologue to A Vision for Horizon 2020: A European Strategic Roadmap for Vision Research and Ophthalmology [1] states: 'Vision researchers should never forget that beyond careers, publications and funding there are patients out there who need and expect a better quality of life: so please, researchers, once in a while close your eyes and imagine what impact an eye-opening research has on people affected by blinding diseases - and keep working for the good cause.'

So what is the purpose of research? Who decides what research should be done? Who decides that purpose: the investigator? The academic department? The university? Industry? The state? The sick? The well?

Science deals with validity [2]. That is, the goal of science is to come up with a finding that accurately reflects the real world. 'Truth' could be defined as 'something in consonance with reality' $[3,4]$. Presumably there is an external reality, and what scientists try to do is to uncover and, if possible, understand that reality. Clinical care, in contrast, deals with relevance. That is, does the finding or the treatment relate appropriately to the issue which needs to be considered? Does it address an important is-

\section{KARGER \\ Fax +4161306 1234 \\ E-Mail karger@karger.ch}

www.karger.com
(C) 2012 S. Karger AG, Basel

$0030-3747 / 13 / 0493-0122 \$ 38.00 / 0$

Accessible online at:

www.karger.com/ore
George L. Spaeth, MD

Glaucoma Service Foundation to Prevent Blindness, Wills Eye Institute

840 Walnut Street, Suite 1130

Philadelphia, PA 19107-5598 (USA)

E-Mail DMalony@willseye.org 
sue? Validity is, unfortunately, less often a concern with clinicians.

Recently there has been great concern about 'conflict of interest' [5-8]. Much of the commentary on conflict of interest has been directed at the corrupting power of industry, which has been accused of funding what it wants, controlling data, manufacturing needs, and influencing practice patterns. In the USA we are now required at the start of every presentation to disclose our financial conflicts of interest. A financial relationship with industry is considered a conflict of interest. But industry is only one source of biased, self-benefitting research. The conflicts that result from industry are no more intense or pervasive than the conflicts whose source is academia. Universities fund what they want, control data, manufacture need, and influence practice patterns. The data from the Ocular Hypertension Treatment Study (OHTS) [9] was not allowed to be seen by anybody except the investigators. When Yale University published Klausen's book The Cartoons that Shook the World [10], they removed the cartoons from the book against the wishes of the author. And surely the scientists in university departments wish to influence practice, such as the development of vaccines for herpes zoster or treatments for acquired immune disease syndrome.

In A Vision for Horizon 2020, four authors list their 5 major priorities for research. These included neuron-glia interaction, gene therapy in retinal diseases, micro-incision cataract surgery, and femtosecond laser surgery, as well as 15 similar issues. One individual mentioned, 'improving care and care delivery in the third world countries'. This entry was so strikingly different from the other 19 priorities that it seemed to be an anomaly.

Who makes the decisions as to what the priorities are: the investigator? The department? The university? Industry? The state? The sick? The well?

It is worth considering how free investigators actually are to choose the projects or discuss the findings which are of importance to them. Around 250 years ago a great Philadelphia physician, Benjamin Rush, made many contributions that benefited mankind. For example, he was one of the first individuals to advocate for the abolition of slavery. He was involved in the founding of the new nation's first hospital. But he also believed passionately in the benefits of bleeding patients, including those with yellow fever; because of his great prestige succeeded in ruining the career of a young physician who performed a study that indicated that patients with yellow fever who were bled were less likely to have a happy outcome than those who were not. I recall being in a meeting in a Euro- pean country when a young woman presented a paper, beautifully organized and supported, indicating that an intraocular pressure above $21 \mathrm{~mm} \mathrm{Hg}$ did not automatically mean glaucoma and below $21 \mathrm{~mm} \mathrm{Hg}$ mean no glaucoma. After the paper was presented, the moderator, the president of one of the major European ophthalmological societies, thanked the young woman but then said: 'But, of course, we all know that if the pressure is above $21 \mathrm{~mm}$ $\mathrm{Hg}$ the patient has glaucoma and below $21 \mathrm{~mm} \mathrm{Hg}$ the patient does not have glaucoma.' Was there any respect for academic freedom? And I recall the personal experience when, at a well-known American university, whose chair was the editor of the Archives of Ophthalmology, I presented information that I thought made a pretty good case for the existence of glaucoma in individuals whose pressures were in the average range. The chair's response was remarkably similar to the European's - totally dismissive of the data. I recall my confusion and distress, as I flew home, trying to figure out how I could have presented the information in a way that was more convincing. The data seemed to be valid, and the conclusion clear. And I also recall a situation in which a young staff member in an equally prestigious American department of ophthalmology wished to participate with another investigator in studying blood flow of the optic nerve in patients with glaucoma, only to be told by his chair that he would not be allowed to do that because studying blood flow in glaucoma would ruin the academic reputation of the department.

Conflicts of interest are universal. Indeed no person would survive if he or she did not honor the conflict of interest that is necessary to lead to personal survival, nor would industry or academia or governments. Conflict of interest is ubiquitous, and it need not be harmful! Consider the stained glass windows in Chartres Cathedral, among the most beautiful in the world and in which there is a marvelous demonstration of conflict of interest, because those paying for the windows had their portrait or their guild clearly shown as part of the window for which they paid. Did that result in a deterioration of the artistic quality or the integrity of the stained glass window? No.

Conflict of interest per se does not need to lead to unrecognized bias or suppression of information. It is how the conflict of interest is handled that is the important issue.

In that regard, it is worth considering whether the recent policies regarding disclosing conflict of interest really help. The answer is probably a resounding no. There is no verification of whether the statements made are true or false. It is not ironic that scientists - dedicated to valid- 
ity - have never validated any statement of a financial conflict of interest. Yet those who are willing to make false statements are those who are most likely to falsify data. Why are they believed?! On the other hand, those who tend to be meticulously honest will disclose many conflicts, perhaps leading the 'audience' to conclude improperly that the presenter is biased. In actuality, present conflict of interest policies are probably counterproductive in terms of science.

Who should set the priorities for research? Who is likely to be most attuned to what really needs to be done: the individual investigator? The department chair? The president of the university? The CEO of the industry? The president of the nation? Or the sick? Or the well?

Some years ago I reviewed a group of internationally recognized journals publishing articles in the field of ophthalmology and vision science [11]. I categorized the articles into 4 different groups: (a) those in which there was an obvious benefit to patients, (b) those in which there was a reasonable chance the patients might someday be benefitted by what was discussed, (c) those in which there was a possible chance that some benefit might eventually arise, and, finally (d) those in which it was clear that there would be no benefit to patients. The ' $d$ ' articles were those that included suggestions as to how to improve the efficiency of an office, etc. The results were: 'a' articles (to benefit patients) 13\%, 'b' articles 30\%, 'c' articles $42 \%$, and those in which there was no apparent benefit to patients whatsoever, $15 \%$.

'The scientists of the world must remember that research is done for the sake of mankind and not for the sake of science; scientists must never detach themselves from the humans they serve' [12]. I applaud this comment, but is it wise? Is it to be followed?

If one reviews the many thousands of titles in the program of the Association for Vision and Research in Ophthalmology meeting in Florida each year, one is hard pressed to see that a majority of the scientists had any interest in keeping themselves closely attuned to the humans the science was supposed to be serving. But is that a valid criticism? Is not science designed to be a search for truth? Is not the scientist committed to trying to understand reality, the implicit belief being that out of an understanding of reality there will be betterment for mankind? But does research to develop methods of spreading avian flu by an aerosol spray or making an atomic bomb benefit society? Should it be allowed? The US government recently prevented publication of an article related to the former issue and subsidized the second. They thought these results of research should be suppressed.
Research now is driven by what one could call the academia-industry complex, or the research establishment. Priorities are certainly not set by mankind, much less by patients.

It is worth considering where ophthalmology research has succeeded and where it has failed. Success: research has led to literally incredible technological advances such as genotyping, and VEGF inhibitors, OCT and phacoemulsification with implantation of posterior chamber intraocular lens implants. But the results have not all been good. There is virtually no better understanding today of how to influence behavior than there was 25,50 , 100 , or 1,000 years ago. Do we have any better ways to encourage people to be honest, not to deny, and to be fair? The answer unfortunately is a disturbingly clear 'no'.

Recognizing that the public opinion of ophthalmologists in the USA was suffering as it became increasingly apparent that ophthalmologists viewed their careers more and more as a business rather than a profession, the American Academy of Ophthalmology decided that residents should be 'taught ethics', and that a certain percentage of continuing medical education credits had to deal with ethics. The result was the development of lectures dealing with 'ethics' and questions on the American Board of Ophthalmology testing to determine whether the residents learned about ethics. But there appeared to be no recognition, no acknowledgement that knowledge about ethics and ethical behavior are two different issues, and that the latter is poorly related to the former. There was no apparent understanding that if the goal was for physicians to act ethically, that is to have behavior considered ethical, lectures would be useless in that regard. Ethical behavior is learned by internalizing experiences shared with ethical mentors.

A powerful article appeared in the British Medical Journal in December 2011 entitled 'The Idolatry of the Surrogate' [13]. The article pointed out that doctors have become invested in surrogate markers. They considered one of the reasons for this to be that the evidence base that physicians had come to use is built from trials that focus on the effect on surrogates. Since surrogates respond sooner than outcomes that are actually important to patients (such as how they feel or how they can act), surrogates are better suited for end points in clinical trials that need to be completed quickly and at a low cost. That type of evidence shapes policy and practice. 'Consequently, clinicians see this evidence converted into guidelines, quality of care measures, and pay for performance targets.' But, as the authors mention, patients do not really care about the thickness of their retinal nerve fiber layer, 
or the level of intraocular pressure. Their concerns are with how they feel and what they can do, yet these are almost never studied. The health research establishment has largely insulated itself from issues that most affect health and that are of most interest to both the sick and the well.

What issues are of most relevance to patients, to the sick and the well? They include premature death, poverty, violence, environmental hardships, and access to care. Those teaching about ethics teach that the three primary principles of medical ethics are (1) beneficence/nonmaleficence, (2) justice (fairness), and (3) autonomy. The responsibility of those interested in health research, then, is to develop data that will result in benefit to the patient, fair allocation of resources, and, probably most important, enhancement of the individual's ability to care for himself or herself.

The Hippocratic oath, still used in many medical schools as something which the graduating students swear to honor, requires physicians to swear that they will not share their knowledge with anyone other than their brethren. To share knowledge with patients or the public is, according to the Hippocratic oath, wrong. Yet the single greatest health issues have always been and still are: (1) how people can learn to take care of themselves properly, and (2) how they can have the facilities to care for themselves properly.

In A Vision for Horizon 2020, one of the authors mentioned as two of the most important contributions the development of small incision cataract surgery and femtosecond laser surgery. But does it really matter in the greater scheme of things whether a patient having a cataract extraction can see $20 / 15$ as opposed to $20 / 20$, or whether he has an accommodative lens or not? Is it just - fair - to be spending a major portion of research dollars on the development of instruments that will make things better for those who already are good and ignore those who are in dire need?

Some years ago, when I was the chair of the Ethics Committee of the American Academy of Ophthalmology, I was charged with the responsibility for investigating the case of Dwight Cavanaugh, who was then the chair of the Department of Ophthalmology at Emory University. I am now free to talk about some aspects of that case, because some of the details were published in a book by Thomas Harbin entitled Waking up blind [14]. Dr. Harbin got a lot of it right, but there was much he did not know. There is no question that Dr. Cavanaugh was doing things that were not admirable: operating on patients who did not need surgery, billing for procedures he did not do, even operating on the wrong eye. When his staff confronted him, he ignored them. So a junior staff member, David Campbell, went to the next academic level, and then to the next, the vice president for medical affairs, and then the Judicial Council. They chastised him, not Dr. Cavanaugh. Eventually, however, Dr. Cavanaugh's lawyer advised Dr. Cavanaugh to step down as chair, as recommended by the Ethics Committee, because the information we had found could be subpoenaed at the time of a court trial (which was certain to happen) and the lawyer realized it was better to 'settle the case' and have the information sealed and unavailable to the court. The place where Harbin gets the story a little wrong is that the real villain in this case was not Cavanaugh. We are all flawed. We are all able to be seduced. We all make mistakes. But those who have the responsibility for supervising us cannot ignore those flaws and mistakes. The administration at Emory was not about to lose a person who brought large sums of research money into the university. Wrong priority!

One could say, as one looks around the world today, that 'academic freedom' is not working very well. The two basic purposes of research are frequently forgotten: (1) to understand what reality actually is, and (2) to benefit living creatures. The brilliance of investigators and the methodology of science need to be merged with the compassion of lovers for their beloved ones so as to produce valid, powerful, relevant outcomes. We do not need less freedom. We need more freedom, freedom to be creative, to take risks, to be what Szent-Gyorgyi call Dionysian investigators. But with that freedom there must be both from the individual researchers and from those deciding what research is going to be done an awareness of their responsibility to encourage, to fund, to supervise, and to publish research that is so excellent that it truly uncovers reality. Even a quick glimpse at today's journals shows that this is by no means always the case. For example, regression analyses are routinely used to make conclusions that are not warranted.

In summary, the methodologies of science can be applied not just to those subjects that are relatively easy to study, but to the truly great issues of mankind: how behavior can be understood so that it can be influenced in a way that individuals will be more caring and less violent. And more specifically for physicians, how physicians can be better guided to make sure that their actions are beneficial, fair, and enhance the ability of each person to care for himself or herself better. 


\section{Disclosure Statement}

I have a financial conflict of interest because I am still a practicing ophthalmologist, and the comments I make will affect whether or not I get referrals. I have an academic conflict of interest because I am an academic, and my comments will affect my academic standing. I have a personal conflict of interest because I believe passionately in what I will be saying, and therefore will be biased. Furthermore, I am aware that I am speaking to an extraordinarily prestigious group of scientists, and I want to say something that will enhance their opinion of me, so I am tempted to make comments that I believe they will want to hear.

\section{References}

1 Wheeler-Schilling TH, Kremer J, Zrenner E: A Vision for Horizon 2020: A European Strategic Roadmap for Vision Research and Ophthalmology. Aechen, Shaker, 2012.

-2 Spaeth GL: Valid relevance in medical practice: the Inadequacy of the linear model of health and disease - the Weisenfeld lecture. Invest Ophthalmol Vis Sci 2011;52:62506256.

3 Webster's Dictionary. http://webster-dictionary.org/definition/Truth.

4 Harry G: On Bullshit. Frankfurt, Princeton University Press, 2005.

5 Coleman D: Establishing policies for the relationship between industry and clinicians: lessons learned from two academic health centers. Acad Med 2008;83:882-887.
6 Angell M: Industry-sponsored clinical research: a broken system. JAMA 2008;300: 1069-1071.

7 Angell M: Relationships with the drug industry: keep at arm's length. BMJ 2009; 338:b222.

8 Coleman D, Kazdin A, Miller L, Morrow J, Udelsman R: Guidelines for interactions between clinical faculty and the pharmaceutical industry: one medical school's approach. Acad Med 2006;81:154-160.

-9 Kass MA, Heuer DK, Higginbotham EJ, et al: The Ocular Hypertension Treatment Study: a randomized trial determines that topical ocular hypotensive medication delays or prevents the onset of primary open-angle glaucoma. Arch Ophthalmol 2002;120:701-713.

10 Klausen J: The Cartoons that Shook the World. New Haven, Yale University Press, 2002.
11 Spaeth GL, Monteiro de Barros DS, Gheith M, Siam GA, Nagarsheth M: How effectively does medical care achieve its purposes? Evaluation of peer-reviewed literature in ophthalmology related to wellness. Trans Am Ophthalmol Soc 2007;105:214-224.

12 Mozes-Kor E: The Mengele twins and human experimentation: a personal account; in Annas GJ, Grodin MA (eds): Nazi Doctors and the Nuremberg Code: Human Rights in Human Experimentation. Oxford, Oxford University Press, 1992, p 58.

13 Yudkin JS, Lipska KJ, Montori VM: The idolatry of the surrogate. BMJ 2011;343:d7995.

14 Harbin T: Waking Up Blind. Washington, Hillcrest Publishing Group, 2009. 